\title{
Cholestatic jaundice, acute kidney injury and acute pancreatitis secondary to the recreational use of methandrostenolone: a case report
}

\author{
Greg A Rosenfeld ${ }^{1 *}$, Albert Chang ${ }^{1}$, Michael Poulin², Peter Kwan and Eric Yoshida
}

\begin{abstract}
Introduction: Over the last few years the use of anabolic steroids has become increasingly common amongst amateur athletes and for aesthetic purposes. As a result, the adverse events related to their use are being seen more frequently. Methandrostenolone is an anabolic steroid which is widely available and has been used for both performance enhancement and aesthetic purposes. This drug has also been reported to cause cholestasis of the intra-hepatic bile ducts resulting in elevated aminotransferases, hyperbilirubinemia and clinical jaundice. However, to the best of our knowledge this agent has not been previously reported to cause pancreatitis or acute kidney injury.
\end{abstract}

Case presentation: In this paper, we report the case of a 50-year-old man of Indian descent who presented with a six week history of diffuse abdominal pain, anorexia and weight loss following an eight week cycle of methandrostenolone use. At initial presentation, his lipase level was $785 \mathrm{U} / \mathrm{L}$, bilirubin was $922 \mu \mathrm{mol} / \mathrm{L}$ and creatinine was $200 \mathrm{U} / \mathrm{L}$ while his aspartate aminotransferase and alanine aminotransferase levels were only mildly elevated at $61 \mathrm{U} / \mathrm{L}$ and $56 \mathrm{U} / \mathrm{L}$ respectively. His lipase peaked on day nine at $>3000 \mathrm{U} / \mathrm{L}$ whilst his creatinine level was 299 U/L. Imaging was consistent with acute pancreatitis while a liver biopsy was consistent with intra-hepatic cholestasis and a kidney biopsy revealed evidence of acute tubular necrosis.

Conclusion: Both acute pancreatitis and acute kidney injury have rarely been reported with anabolic steroid use and they have not been previously reported to occur in the same patient. This case demonstrates some potentially new and serious adverse consequences occurring with the use of anabolic steroids, of which physicians need to be aware.

\section{Introduction}

Anabolic androgenic steroids (AAS) have been in widespread use amongst elite athletes to enhance performance for decades [1]. Major League Baseball and the National Football League have provided numerous examples of steroid use amongst their professional athletes. Several Olympic athletes have tested positive for the use of AAS or admitted to their use [2]. Meanwhile, the Vancouver 2010 Winter Olympic games saw the creation of the most sophisticated anti-doping testing laboratory to date, resulting in 30 athletes testing

\footnotetext{
* Correspondence: grosenfeld@telus.net

'Department of Medicine, University of British Columbia, 5th Floor, Gordon and Leslie Diamond Health Care Centre, 2775 Laurel St, Vancouver, BC, V5Z 1M9, Canada

Full list of author information is available at the end of the article
}

positive and being banned from attending the games prior to their opening. With the knowledge of widespread steroid use has come an increased awareness of the adverse effects and sometimes serious consequences of AAS use. Nevertheless, there seems to be an ever increasing use of these agents by recreational athletes and for aesthetic purposes. Recent estimates place AAS use in the USA and Sweden at 1\% of the population and we can reasonably assume that the rates of use in Canada are similar [1]. The internet has increased the black market availability of these drugs without prescription and consumers are frequently unaware of the risks of taking these drugs.

Methandrostenolone (Dianabol) was first introduced as an anabolic steroid by Ciba in the 1960s. Methandrostenolone was one of the AAS used to enhance

\section{Ciomed Central}


athletic performance by the former East German Olympic program [3]. This agent has numerous side effects common to anabolic androgenic steroids which include gynecomastia, acne, mood changes (aggressiveness) and testicular atrophy [4]. Stanozolol, another carbon-17alkylated anabolic steroid, has been previously reported to cause severe cholestasis and acute renal failure in a young athlete [5]. Acute kidney injury arising from the use of anabolic steroids and vitamin supplementation in two male athletes has also been recently reported [6].

Methandrostenolone has also been reported to cause cholestasis of the intra-hepatic bile ducts resulting in elevated aminotransferases, hyperbilirubinemia and clinical jaundice [7]. In this paper, we present a case of pancreatitis, cholestasis of the liver and acute kidney injury associated with the use of methandrostenolone for aesthetic purposes in a 50-year-old, non-athlete man. A brief literature review of Medline and PubMed Central, utilizing the search terms 'androgenic anabolic steroids', 'pancreatitis' and 'methandrostenolone', failed to reveal any other cases of pancreatitis arising from the use of anabolic steroids.

\section{Case presentation}

A 50-year-old man of Indian descent, known to have mild, chronic hepatitis $\mathrm{C}$, presented with a two week history of diffuse abdominal pain. Six weeks prior to the onset of the pain, he had a gradual onset of anorexia and a 20 pound weight loss. Our patient noticed darkly coloured urine and pale stools beginning around the time of the onset of pain. He had not received treatment for his hepatitis $\mathrm{C}$ infection. He had intermittent and occasionally heavy alcohol consumption on weekends. He had also been taking methandrostenolone: $10 \mathrm{mg}$ orally twice a day, five days a week for three weeks and then three times a day, five days a week for the next five weeks, for a total of eight weeks immediately prior to presentation.

When he presented, his white blood cell count was 9.8 giga/L (normal range 4.0-11.0 giga/L), his hemoglobin level was $172 \mathrm{~g} / \mathrm{L}$ (normal range 135-170 g/L) and his platelet levels were 378 giga/L (normal range 150-400 giga/L). His lipase level was $785 \mathrm{U} / \mathrm{L}$ (normal range 0$393 \mathrm{U} / \mathrm{L}$ ), gamma-glutamyltransferase (GGT) level 24 U/ $\mathrm{L}$ (normal range 15-80 U/L), alkaline phosphatase (ALP) level 154 U/L (normal range 50-160 U'L), total bilirubin level $922 \mu \mathrm{mol} / \mathrm{L}$ (normal range $0-18 \mu \mathrm{mol} / \mathrm{L}$ ), with direct bilirubin $804 \mu \mathrm{mol} / \mathrm{L}$ (normal range $0-5 \mu \mathrm{mol} / \mathrm{L}$ ), alanine aminotransferase level (ALT) $56 \mathrm{U} / \mathrm{L}$ (normal range $25-80 \mathrm{U} / \mathrm{L}$ ), aspartate aminotransferase (AST) level $61 \mathrm{U} / \mathrm{L}$ (normal range 10-38 U/L) and lactate dehydrogenase level $242 \mathrm{U} / \mathrm{L}$ (normal range 90-210 U/ L). His international normalized ratio was 1.1 and serum albumin level was $35 \mathrm{~g} / \mathrm{L}$ (normal range 34-50 g/ $\mathrm{L})$. He was also noted to have an element of acute renal failure with a serum creatinine level of $200 \mu \mathrm{mol} / \mathrm{L}$ (normal range 60-115 $\mu \mathrm{mol} / \mathrm{L}$ ) (Table 1 ). He had no previous history of renal disease. He was admitted to our hospital for supportive management and further investigations.

A non-contrast computed tomography (CT) scan of his abdomen was performed shortly after admission which showed mild fatty infiltration of the liver. There was no evidence of inflammatory fat stranding around his pancreas or kidneys. An ultrasound of his abdomen performed 48 hours later showed mild hepatic enlargement with his liver measuring $17.1 \mathrm{~cm}$ in length with a coarse, echogenic texture. There were no focal hepatic lesions or intra-hepatic duct dilatation. There was a small amount of sludge in his gallbladder but no stones. His common bile duct was of normal caliber at $2 \mathrm{~mm}$ in diameter. His pancreas was well seen and unremarkable. His renal parenchyma was echogenic and measured at the upper limits of normal size which was in keeping with medical renal disease.

Within a couple of days of admission, our patient began to experience worsening nausea, vomiting and abdominal pain. His serum lipase level declined over the first three days, but it later began to rise and peaked on day nine at $>3000 \mathrm{U} / \mathrm{L}$, while his ALP level also peaked on day eight at $206 \mathrm{U} / \mathrm{L}$. His ALT and AST levels remained only mildly elevated. Our patient's creatinine level rose to a peak of $299 \mu \mathrm{mol} / \mathrm{L}$ on day nine.

Serum auto-antibodies, serum protein electrophoresis and cryoglobulins were all negative. Human immunodeficiency virus antibodies were negative however, as anticipated, his hepatitis C viral RNA was qualitatively positive. His fasting serum lipid levels were low with the exception of triglycerides which were mildly elevated at $3.25 \mathrm{mmol} / \mathrm{L}$ (normal range $0.60-2.30 \mathrm{mmol} / \mathrm{L}$ ). Our patient's clinical picture was most consistent with acute pancreatitis and thus, a non-contrast (due to renal failure) CT scan of his abdomen was obtained on the tenth day. This showed a bulky pancreas with adjacent inflammatory fat stranding which was interpreted as consistent with pancreatitis without a focal drainable abscess. There were also no signs of chronic pancreatitis.

Our patient went on to have a liver biopsy which revealed grade 2 portal and lobular inflammation, stage 2-3 fibrosis consistent with hepatitis $C$ viral infection, moderately severe acute cholestasis consistent with anabolic steroid use, and mild pericellular fibrosis consistent with alcohol abuse but without evidence of steatosis or steatohepatitis (Figure 1). A renal biopsy was also performed which showed acute tubular injury of uncertain etiology. His glomeruli were normal and there was evidence of desquamation of his tubular epithelial cells. Therefore, acute tubular necrosis was confirmed as the etiology of his renal failure. 
Table 1 Table showing laboratory values over time in hospital and in the first few weeks post discharge

\begin{tabular}{|c|c|c|c|c|c|c|c|c|c|c|c|}
\hline & WBC & HGB & BUN & $\mathrm{CR}$ & AMYLASE & LIPASE & GGT & ALP & BILI & ALT & AST \\
\hline Admission & 8.8 & 172 & 13.2 & 200 & & 785 & 24 & 154 & 922 & 56 & 61 \\
\hline Post admission Day 1 & 12.5 & 148 & 11.9 & 175 & & 634 & 13 & 133 & 755 & 45 & 51 \\
\hline Day 2 & & 158 & 10.9 & 171 & & & 38 & 161 & 869 & 45 & 53 \\
\hline Day 3 & 10.8 & 160 & 11.3 & 185 & 71 & 968 & 10 & 135 & 739 & 33 & 42 \\
\hline Day 4 & 11.5 & 164 & 13.8 & 199 & 29 & 345 & 24 & 172 & 919 & 46 & 72 \\
\hline Day 5 & & & 16.7 & 290 & 47 & 417 & 18 & 182 & 937 & 48 & 67 \\
\hline Day 6 & 10.9 & 153 & 19.7 & 288 & 50 & 461 & 14 & 180 & 896 & 52 & 67 \\
\hline Day 7 & 13.9 & 170 & 24.5 & 298 & 141 & 1629 & 24 & 206 & 804 & 56 & 70 \\
\hline Day 8 & 16 & 161 & 24.3 & 291 & 1855 & $>3000$ & 16 & 165 & 678 & 44 & 73 \\
\hline Day 9 & 14.1 & 136 & 26.4 & 299 & 1720 & $>3000$ & 8 & 171 & 660 & 64 & 96 \\
\hline Day 10 & 17.1 & 137 & 22 & 246 & 841 & $>3000$ & 8 & 151 & 544 & 47 & 54 \\
\hline Day 11 & 17.2 & 127 & 15 & 206 & 343 & $>3000$ & 9 & 161 & 532 & 44 & 48 \\
\hline Day 12 & 15.8 & 121 & 12.3 & 179 & & & 9 & 159 & 473 & 35 & 45 \\
\hline Day 13 & 16.2 & 120 & 9.6 & 161 & & & 9 & 146 & 447 & 28 & 36 \\
\hline Day 14 & 18.7 & 123 & 9.4 & 153 & & & 9 & 119 & 424 & 27 & 38 \\
\hline Day 15 & 17.3 & 109 & 9 & 160 & & & 13 & 145 & 409 & 33 & 44 \\
\hline Day 16 & 20.7 & 111 & 7.9 & 136 & & & 13 & 122 & 302 & 24 & 31 \\
\hline Day 17 & & & & 140 & 68 & 412 & 11 & 136 & 247 & 29 & 37 \\
\hline Day 18 & 18.6 & 112 & 5 & 120 & & & 14 & 1483 & 166 & 32 & 37 \\
\hline Discharge (Day 19) & 13.5 & 102 & 5.1 & 131 & & & 13 & 130 & 136 & 33 & 37 \\
\hline $\begin{array}{l}\text { At follow up } \\
\text { (Day 38) }\end{array}$ & 11.8 & 131 & 4 & 119 & 64 & 237 & 23 & 145 & 53 & 92 & 59 \\
\hline (Day 39) & 10.5 & 125 & 3.9 & 103 & 46 & 170 & 17 & 128 & 50 & 84 & 67 \\
\hline
\end{tabular}

With supportive therapy, our patient's pancreatitis began to resolve and he was asymptomatic at the time of discharge. One month after discharge, his renal function had returned to normal and his amylase $(46 \mathrm{U} / \mathrm{L})$, lipase (270 U/L), GGT (17 U/L), and ALP (128 U/L) levels had all returned to normal. His total bilirubin

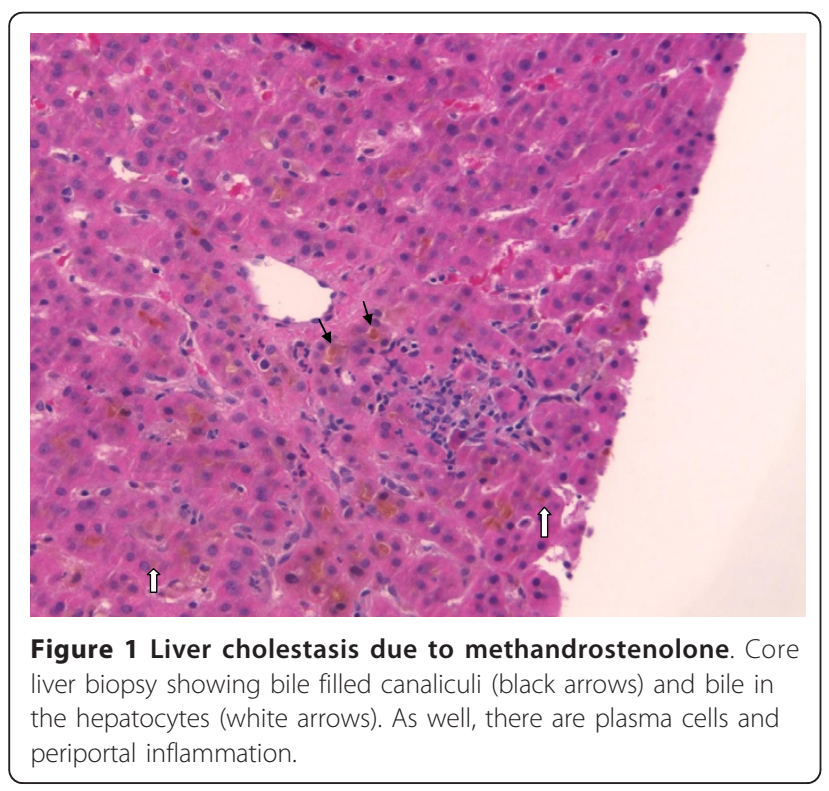

level remained mildly elevated at $50 \mu \mathrm{mol} / \mathrm{L}$ and his ALT (84 U/L) and AST (67 U/L) levels were also mildly elevated in keeping with his chronic hepatitis C infection.

\section{Discussion}

AAS use or misuse is no longer solely by elite athletes seeking enhanced performance. Teenage boys in Sweden reported using AAS for a variety of reasons [8], while bodybuilders, weight-lifters and prison populations have also been shown to have higher levels of misuse [9]. Our patient took AAS not for athletic performance but for aesthetic reasons. He reported wanting to "remain in shape" as the main reason for taking these pills. Anabolic steroids are readily available to the general public over the internet and at public gyms, they are easily obtained illegally, without a prescription. As a result, patients are less likely to report taking AAS to their physician and physicians are less likely to consider the possibility of the use of AAS in the non-athlete population.

Our patient represents the first case of a patient developing pancreatitis as a result of anabolic androgenic steroid use. A recent clinical workshop reviewed the criteria necessary for reporting cases of Drug Induced Liver Injury [10]. We believe that this case report meets those criteria and we have reported on all of the 
necessary elements and many of the supportive elements outlined in the summary document emanating from that workshop. The usual causes of pancreatitis were excluded in our patient. He did not have any evidence of gallstones on repeated imaging studies, nor were his alkaline phosphatase or GGT significantly elevated as would be expected with obstructing gallstones. His triglyceride levels were only mildly elevated and not to the degree usually seen with pancreatitis. He had been hospitalized for four days before the first sign of pancreatitis and had not consumed alcohol for at least a week at that time. Given that his liver biopsy confirmed a cholestatic picture consistent with steroid use, we conclude that this was the main contributing factor in the pathogenesis of his pancreatitis. His hepatitis $\mathrm{C}$ may have made him more prone to liver injury from steroid use but the relatively low elevation of transaminases suggests that his hepatitis $C$ infection was quite mild and stable. Furthermore, his liver biopsy showed a cholestatic pattern much more in keeping with steroid use than hepatitis $C$ infection.

Our patient's acute kidney injury is unique in that the pathology showed acute tubular necrosis (ATN). In two previous case reports with anabolic steroid use and vitamin supplementation as the cause of acute kidney injury, the biopsies showed acute interstitial nephritis [6]. In these cases, the kidney injury was attributed to the supplementation of vitamin D with resultant hypercalcemia as the mechanism of kidney injury. Excessive vitamin intake and hypercalcemia were not factors in our patient. The extremely high bilirubin level found in our patient is consistent with a previously reported case of severe cholestasis and ATN secondary to AAS use [5]. In that report, the proposed mechanism of ATN was secondary to severe cholestasis and the increased renal excretion of bilirubin. Two additional cases of acute kidney injury associated with the use of an over-the-counter nutritional supplement (Superdrol ${ }^{\mathrm{TM}}$ ) have been reported $[11,12]$. In the first case a kidney biopsy was not performed, while the second case reported a biopsy consistent with IgA nephropathy [12]. Whatever the exact mechanism, our patient's history is most consistent with his AAS use as the main culprit in both his acute kidney injury and pancreatitis.

\section{Conclusion}

AAS use and misuse is being seen in an expanding population of patients because they are readily available and often perceived as safe. The side effects and risks of taking AAS are difficult to assess in controlled trials due to the unethical nature of administering these drugs in the doses usually taken by patients who use them for aesthetic or athletic purposes. As a result, with the increasing use of these drugs, we can expect to see an increase in previously unreported adverse consequences.
Although there have been previous reports of severe cholestasis and jaundice with the recreational use of anabolic steroids [13], this is the first case report where acute pancreatitis and acute kidney injury also resulted from such recreational use. Physicians need to be aware of the risks to their patients who consume AAS, and to consider that even with only mild elevations of aminotransferases, serious consequences such as cholestasis, acute kidney injury and pancreatitis may result.

\section{Consent}

Written informed consent was obtained from the patient for publication of this case report and any accompanying images. A copy of the written consent is available for review by the Editor-in-Chief of this journal.

\section{Author details}

'Department of Medicine, University of British Columbia, 5th Floor, Gordon and Leslie Diamond Health Care Centre, 2775 Laurel St, Vancouver, BC, V5Z 1M9, Canada. ${ }^{2}$ Department of Pathology, Vancouver General Hospital, 889 West 12th Avenue, Vancouver, BC, V5Z 1M9, Canada.

\section{Authors' contributions}

GR and $A C$ were major contributors in writing the manuscript. EY and PK analyzed and interpreted the patient data regarding the patient's presentation and provided the clinical care of the patient. MP performed the histological examination of the liver biopsy and prepared the figure for the manuscript. All authors contributed to the writing of the manuscript and approved the final version.

\section{Competing interests}

The authors declare that they have no competing interests.

Received: 28 June 2010 Accepted: 6 April 2011 Published: 6 April 2011

\section{References}

1. Sjöqvist F, Garle M, Rane A: Use of doping agents, particularly anabolic steroids, in sports and society. Lancet 2008, 371(9627):1872-1882.

2. Associated Press: IOC Strips Jones of All 5 Olympic Medals. [http://nbcsports.msnbc.com/id/22170098/], (Last updated at 9.00 ET 12th December 2007).

3. Franke $W W$, Berendonk B: Hormonal doping and androgenisation of athletes: a secret program of the German Democratic Republic government. Clin Chem 1997, 43(7):1262-1279.

4. Evans N: Current Concepts in Anabolic Androgenic Steroids. Am J Sports Med 2004, 32(2):534-542.

5. Yoshida EM, Karim MA, Shailh JF, Soos JG, Erb SR: At what price, glory? Severe cholestasis and acute renal failure in an athlete abusing stanzolol. CMAJ 1994, 151(6):791-793.

6. Daher EF, Silva Júnior GB, Queiroz AL, Ramos LM, Santos SQ, Barreto DM, Guimarães AA, Barbosa CA, Franco LM, Patrocínio RM: Acute kidney injury due to anabolic steroid and vitamin supplement abuse: report of two cases and a literature review. Int Urol Nephrol 2009, 41(3):717-723

7. Stang-Voss C, Appell HJ: Structural alterations of liver parenchyma induced by anabolic steroids. Int J Sports Med 1981, 2(2):101-105.

8. Nilsson S, Baigi A, Marklund B, Fridlund B: The prevalence of the use of androgenic anabolic steroids by adolescents in a county of Sweden. Eur J Public Health 2001, 11(2):195-197.

9. Thilibin I, Petersson A: Pharmacoepidemiology of anabolic androgenic steroids: a review. Fundam Clin Pharmacol 2005, 19(1):27-44.

10. Fontana RJ, Seeff LB, Andrade RJ, Bjornsson E, Day CP, Serrano J, Hoofnagle JH: Standardization of nomenclature and causality assessment in drug-induced liver injury: summary of a clinical research workshop. Hepatology 2010, 52(2):730-742. 
11. Nasr J, Ahmad J: Severe cholestasis and renal failure associated with the use of the designer steroid Superdrol (methasteron): a case report and literature review. Dig Dis Sci 2009, 54(5):1144-1146.

12. Jasiurkowski B, Raj J, Wisinger D, Carlson R, Zou L, Nadir A: Cholestatic jaundice and IgA nephropathy induced by the otc muscle building agent Superdrol. Am J Gastroenterol 2006, 101(11):2659-2662.

13. Yoshida EM, Erb SR, Scudamore CH, Owen DA: Severe Cholestasis and Jaundice Secondary to an Esterified Testosterone, a Non-C17 Alkylated Anabolic Steroid. J Clin Gastroenterol 1994, 18(3):268-270.

doi:10.1186/1752-1947-5-138

Cite this article as: Rosenfeld et al: Cholestatic jaundice, acute kidney injury and acute pancreatitis secondary to the recreational use of methandrostenolone: a case report. Journal of Medical Case Reports 2011 5:138.

\section{Submit your next manuscript to BioMed Central} and take full advantage of:

- Convenient online submission

- Thorough peer review

- No space constraints or color figure charges

- Immediate publication on acceptance

- Inclusion in PubMed, CAS, Scopus and Google Scholar

- Research which is freely available for redistribution

Submit your manuscript at www.biomedcentral.com/submit 